\title{
The Flower Report: Libraries without walls - (almost) 20 years later
}

\author{
Trish Chatterley
}

\begin{abstract}
In the 1987 report Libraries Without Walls: Blueprint for the Future, Muriel Armstrong Flower put in writing her vision for a library that was open to all Canadians. This paper discusses Flower's recommendations and their outcomes and offers commentary about the current state of Canadian health sciences librarianship. It also outlines recent progress made towards equality of access to health information for all.
\end{abstract}

In 1987, Muriel Armstrong Flower put in writing her vision for a library without walls - a library that was open to all Canadians. A joint project of the Special Resource Committee on Medical School Libraries (SRCMSL) of the Association of Canadian Medical Colleges (ACMC) and the Canadian Health Libraries Association / Association des bibliothèques de la santé du Canada (CHLA / ABSC), the report provided a summary of issues faced by health sciences libraries as well as recommendations for future progress [1]. Almost 20 years later, Canadian health sciences libraries are well on their way to making Flower's vision a reality. This paper discusses the outcome of Flower's recommendations and offers commentary about the current state of Canadian health sciences librarianship.

Libraries Without Walls: Blueprint for the Future, itself an update of an earlier report written by Beatrice Simon in 1964, presented the results from a nationwide survey of health sciences libraries. This report was peppered with Flower's recommendations for the future. Of those, five were explicitly stated as essential to ensure progress in Canadian libraries:

(1) that a task force on harnessing technology for health sciences information be established, with the Canada Institute for Scientific and Technical Information (CISTI) and SRCMSL leading the endeavour to design an interactive, integrated, and nationwide library system

(2) that deans of medicine at each medical school establish an information management council to deal with information provision in the health sciences region served

(3) that a joint SRCMSL-CHLA committee be established to study interlibrary loans in the health science sector and to make recommendations on ways to manage volume, to rationalize costs, and to improve delivery time

(4) that a working party be struck to review and explore present and potential future sources of financing for health science libraries in Canada

T. Chatterley. John W. Scott Health Sciences Library, Walter C. Mackenzie Health Sciences Centre, University of Alberta, Edmonton, AB T6G 2R7, Canada (e-mail: patricia.chatterley@ualberta.ca).
(5) that the Health Sciences Resource Centre at CISTI be maintained and strengthened with the institution of a CISTI Fellowship Program and secondments for the head librarian

It seems as though only one of the five recommendations came to fruition. A joint SRCMSL-CHLA committee was established in 1989 to "examine methods of handling interlibrary loan traffic, improving delivery time, and rationalizing costs" [2]. The committee discovered that the systems in operation at the time were inadequate to meet demand and that there was no mandate to ensure equitable access to interlibrary loan services across types and sizes of libraries. The work of the committee was continued by a CHLA / ABSC Task Force on Resource Sharing in the mid-1990s, following the introduction of DOCLINE to Canada in 1993, and by a second task force later in the decade.

The other suggested improvements based on Flower's proposals were never instituted. In retrospect, when looking at the evolution of health sciences librarianship, they may not have been crucial to progress, and there were often other measures taken that produced an equivalent effect. Although the task force on harnessing technology was never generated, the CISTI Committee on Health Sciences Information was formed to provide specialized advice regarding plans, priorities, programming, and services in general [3]. The task force was not required, as the adoption of technology has simply followed a natural course in the library world. Information management councils in health sciences centres were never established, but nevertheless regional systems for information provision have been formed around most medical school libraries. Instead of the Health Sciences Resource Centre (HSRC) at CISTI being maintained and strengthened in subsequent years, the centre was in fact closed in 1993 [4]. However, though many librarians might have disagreed with the decision at the time, in the long term there was no ill effect. The main role of HSRC staff was to facilitate access and provide passwords and training on the old National Library of Medicine ELHILL search system. With the advent of numerous other health sciences databases available through online vendors such as Ovid, EBSCO, ProQuest, 
Dialog, and others, and free Web-based access to PubMed as of June 1997, support requirements for ELHILL declined dramatically even before the system was withdrawn in 1999 , thereby eliminating one of the main services of the HSRC.

The HRSC's other main purpose, to respond to requests for information resources, also became less important when CISTI became the Canadian coordinator for DOCLINE to oversee and support the smooth provision of interlibrary loans (L. Slater, personal communication, 2006). A working party to investigate sources of financing was never struck. Given the immensity of such a task, it is unlikely that it could have been accomplished effectively by a group at that level. Library budgets were being reduced because of institutional budget cuts. This problem was compounded by drastic increases in journal subscription prices and the concurrent drop in the value of the Canadian dollar. More recently, the funding situation in Canada was dealt a devastating blow in January 2006 with the announcement by Health Canada that it would be cutting the budget of its six Ottawa-based health sciences libraries to the point where library staff might have to be reduced by as much as $60 \%$ [5]. The need for a task force to investigate potential funding sources may be more necessary now than ever, especially for hospital, association, and government libraries, as the proliferation of information resources on the Internet continues to be seen by many as a valid alternative to developing library collections.

Despite the lack of progress in implementing the Flower Report's recommendations, products and services in health sciences libraries have improved immensely over the past 20 years. No one could have imagined just how far technological advances would take the field of librarianship. From a time in 1987, when computers were just starting to be phased into university curriculum, to today, when students are technological whizzes with their laptops, personal digital assistants (PDAs), and cell phones, provision of library services has of necessity been radically altered. Flower recognized even then that librarians would don more of a teaching role as computers began to take over many staff and user functions and online searching became more complex. This trend continues today. There has been much speculation about whether or not the abundance of information made freely available over the Internet will lead to the obsolescence of libraries and librarians. This is not true; our roles will simply have to be revised. Most processes are now automated, and as they become more rapid and efficient, librarians have more time to become increasingly involved in instruction. Patrons have become confused by the plethora of resources available to them and therefore must be taught which resources to use and how to use them. They must be instructed to appraise literature critically and not simply turn to their favourite search engine to seek answers to their questions. Librarians must now package and present resources in ways that make sense to library users so we do not end up with a generation of doctors and nurses who use Google to make diagnoses and choose appropriate therapies.

There must be a means to learn the new and ever-changing responsibilities of the health sciences librarian. Flower recognized the need for "professional preparation and continuing education" [1], a need that is just as essential today. Health sciences librarianship is indeed a specialty that requires special training. Thankfully, this need has been recog- nized by many library schools across Canada. A quick look at the curricula will reveal courses under various titles related to health sciences literature and information sources at the University of British Columbia, University of Alberta, University of Toronto, University of Western Ontario, McGill University, and Dalhousie University. Although not required courses, they provide an excellent introduction to the field for anyone interested in pursuing a career in health sciences librarianship. Courses in information technology are now mandatory everywhere as computers and technological innovations are now integral elements of library functions and service.

In 1987, Flower reported that only five of 16 medical school libraries in Canada had online public access catalogues (OPACs) and that fax machines were the latest new development. An interlibrary loan experiment between the University of Alberta and the Nova Scotia Provincial Library had recently been undertaken, the results of which indicated that an extremely high volume of reciprocal borrowing would be required to justify the high cost of facsimile equipment. In 2006, this is amusing as fax machines today have largely been replaced by newer and better quality equipment. Ariel systems enable much higher resolution copies of articles to be sent across countries and continents. OPACs have become the norm with card catalogues still existing in only the smallest of libraries, and those OPACs are now accessible on any personal computer with an Internet connection.

Flower reported that library patrons' expectations for rapid delivery of information were already on the rise as many had "microcomputers" on their desks and were eager for the library to participate in electronic communication. The invention of the Internet has been a great enabler for libraries, allowing almost immediate access to large bodies of literature. Flower stated that "it should be possible to identify the item required, find it in the collection, order it, and have it on their desk tomorrow" [1]. Now, especially in larger institutions, it is possible to have required items in users' hands within minutes. The vast majority of journals are now available electronically, and most patrons expect that they will be able to find what they want online, sometimes becoming irritated when they actually have to come to the physical (rather than virtual) library if an item they want is only available in print. Most databases are available via Web-based platforms, enabling patrons to conduct their own searches instead of requiring librarians to conduct expensive, pay-per-minute searches for them. The Internet has improved efficiency in other ways as well, facilitating global communication and remote access to the library's resources.

Though she could not have fully foreseen what shape the electronic revolution would take, it is this revolution that led Flower to believe that it would be possible to achieve nationwide cooperation and equal access to health information for all. In the past, hospital libraries were at a disadvantage when compared with academic ones, usually with smaller budgets and hence smaller collections and staff complements. While this situation is often still true today, the formation of consortia and regional library systems has served to alleviate this inequity. Flower envisioned a nation wherein the 16 medical school libraries across the country would serve as the nuclei of regional, integrated partnerships [1]. The two types of libraries would complement each other, 
with the university's resources in support of teaching and research being supplemented by the hospital's clinical and patient care materials. Of the now 17 medical schools (the Northern Ontario School of Medicine joined the Association of Faculties of Medicine of Canada in 2004) [6], all but one school have such regional systems in place.

These regional library systems are often further supported by provincial resource-sharing initiatives, many of which were created to alleviate the problems caused by budgetary cuts, that aim to foster equitable access to health information. For instance the Health Knowledge Network in Alberta, the Saskatchewan Health Information Resources Partnership, and the Atlantic Health Knowledge Partnership, among others, facilitate licensing of and therefore access to various electronic resources for members of health and library institutions and organizations across their respective provinces that might otherwise not be able to afford such products. By delivering patient care information and the results of the latest research ventures, such a system allows health practitioners across the country to provide evidencebased practice to their patients. The National Network of Libraries for Health, should it be established as we all hope, will provide a similar service but on a national scale, bringing electronic access to health care providers in disparate situations across the country.

International networks are also working towards the goal of ensuring equitable access. The Health InterNetwork Access to Research Initiative (HINARI), is a World Health Organization initiative that provides institutions in developing countries with free or very low-cost electronic access to the world's major biomedical and social sciences journals. Now the remaining problem is the provision of enough computers and Internet connections to enable access to the online resources. Currently over 70 publishers contribute their content to HINARI and this number is continually increasing [7]. Perhaps one day, there will be a global network providing free electronic access to everyone around the world. The various open access initiatives are already making progress towards such a goal. Online repositories such as BioMed Central and the Directory of Open Access Journals (DOAJ) are working to enable free access for all to high quality information and research. As these ventures continue to increase in number and scope, we come ever closer to worldwide information equality.

In 1987, Muriel Flower had a vision for the future: electronic access to resources would enable Canadians to have equal access to online health information [1]. Although many of her recommendations were not implemented, I think she would still be impressed by the advancements in health sciences librarianship both in Canada and around the world. Although we have not yet fully achieved a universal library, monumental progress has been made toward that end and perhaps in another 20 years, we will indeed have not just a national, but an international library without walls.

\section{References}

1. Flower MA. Libraries Without Walls: Blueprint for the Future. Toronto: Association of Canadian Medical Colleges, Canadian Health Libraries Association; 1987.

2. Beck C. Resource Sharing in the Health Libraries. Natl Libr News [serial online]. 1996 Sept [cited 2006 Oct 20];28 [1 screen]. Available from http://www.collectionscanada.ca/bulletin/ 015017-9609-02-e.html.

3. The Canada Institute for Scientific and Technical Information (CISTI) Committee on Health Sciences Information [Web page]. 2005 Sept [cited 2006 Oct 20]. Available from http://cisti-icist. nrc-cnrc.gc.ca/sante/committee_e.html.

4. Ellis P. Timeline of the delivery of health knowledge in Canada, related events in the USA and the world, and additional contemporaneous events. J Can Health Libr Assoc. 2005;26:61-9.

5. Budget cuts at Health Canada gut research libraries [article online]. 2006 Jan [cited 2006 Oct 20]. Available from http://www.cbc.ca/ canada/ottawa/story/2006/01/09/ot-healthcuts20060109.html.

6. Association of Faculties of Medicine of Canada (AFMC) [Web page]. [cited 2006 Oct 20]. Available from http://www.afmc.ca/ pages/about.html.

7. World Health Organization (WHO). HINARI Access to Research Initiative [online]. [cited 2006 Oct 20]. Available from http://www.who.int/hinari/about/en/. 